\title{
Educational Resources for Preservice Anesthesia Training Programs in Amhara Region, Ethiopia
}

This article was published in the following Dove Press journal:

Advances in Medical Education and Practice

\author{
Tikuneh Yetneberk (iD) \\ Yophtahe Woldegerima ${ }^{2}$ \\ Habtamu Getnet (D) ${ }^{2}$ \\ Mamaru Mollalign (iD ${ }^{2}$ \\ Meseret Firde' \\ Jolene N Moore $\mathbb{B D}^{3}$ \\ 'Department of Anesthesia and Critical \\ Care, Debre Tabor University, Debre \\ Tabor, Ethiopia; ${ }^{2}$ Department of \\ Anesthesia and Critical Care, University \\ of Gondar, Gondar, Ethiopia; ${ }^{3}$ College of \\ Life Sciences \& Medicine, University of \\ Aberdeen, Aberdeen, UK
}

Correspondence: Tikuneh Yetneberk Department of Anesthesia and Critical Care, Debre Tabor University, PO Box 272, Debre Tabor, Ethiopia

Tel +251923525309

Email tikusosi@gmail.com
Background: Across low and middle-income countries, shortages of essential equipment, supplies, and human resources in health training institutions pose a problem to educational program delivery. With the rapid expansion of anesthesia training programs to address the shortages in anesthesia workforce, the need for educational resources has also grown. This study sought to evaluate the availability of educational resources within anesthesia degree programs in Ethiopia.

Methods: Utilizing the Higher Education Relevance and Quality Agency of Ethiopia standards, a questionnaire survey was designed and distributed to schools of anesthesia in the Amhara region. A total of 96 standard indicators were used to assess the attainment of preservice educational resources for non-physician anesthesia degree programs, of which 71 (74\%) were basic standards and 25 (26\%) were standards for quality improvement.

Results: Two of the six institutions delivering anesthesia training in the Amhara region responded to the questionnaire. Neither the basic nor the quality improvement standard requirements for educational resources were completely achieved in any category of classrooms, offices, skills laboratory, clinical practice site, information technology facilities, library, student amenities, or financial resource. The target achievement rate was $50 \%$ or below in all but one category (clinical practice site).

Conclusion: Educational resources for responding preservice anesthesia training programs in the Amhara region of Ethiopia are inadequate and below the required national standards. Expansion of anesthesia training programs should be accompanied by the necessary resources for high quality program delivery and to ensure quantity does not compromise on quality.

Keywords: health education, anesthesia training, preservice education

\section{Introduction}

The preservice education of a health worker prior to deployment into the healthcare system is of paramount importance to ensure all health workers begin their careers with a foundation built on competence and are prepared to be lifelong learners and potential leaders. ${ }^{1}$ Across low and middle-income countries, shortages of essential equipment, supplies, and human resources in health training institutions may pose a problem. Efforts to address shortages of health workers in low resource settings have focused on rapidly increasing the number of higher education programs for health workers. ${ }^{2}$ Rapid increases in the number and size of training programs for health professionals in low and middle-income countries demands material and human resource inputs. ${ }^{3}$

In response to a national shortage of anesthesia professionals, the Ethiopian government has focused significant efforts over the last decade to address this by 
expanding education programs and training opportunities for anesthetists. ${ }^{2,3}$ This rapid expansion of training has added strain on anesthesia education institutions, with faculty, equipment, and infrastructure in short supply.

An effective learning environment requires a sufficient number of teaching and learning tools for the student cohort, physical space for classrooms, and an area where students can access resources for private study, whether a library, computer lab, or combination. ${ }^{1}$ Clinical learning environments, including quality of teaching, supervision, and facilities, are associated with achievement in medical education. ${ }^{4}$ Widespread deficits in the learning environment of anesthesia training programs have been reported in Ethiopia with opinions of the curriculum, facilities, and clinical practicum predominantly critical, citing crowded programs, unmotivated students, under-equipped skills labs, and poorly coordinated clinical sites that do not have adequate case exposure and opportunities to develop clinical competencies. ${ }^{3}$

With the shift in focus of anesthesia education from knowledge-based to competency-based, educators are placing increasing emphasis on the role of simulation in the education process. ${ }^{5}$ Simulation-based performance assessment has been validated for identifying critical gaps in anesthesia trainee's performance early in training. ${ }^{6}$ Despite increased focus on low-fidelity simulation in low resource settings, the availability of skills laboratories and simulation equipment is important to enable skills development.

The Ethiopian Higher Education Relevance and Quality Agency (HERQA) was established in 2003 under the Higher Education Proclamation (HEP) by the government of Ethiopia in order to ensure quality of higher education amid rapid expansion sets recommendations for quality assurance in higher education. HERQA has set a framework of standards for audit of higher education institutions. Utilizing these quality indicators, this study sought to evaluate the availability of educational resources within anesthesia degree programs in the Amhara region of Ethiopia.

\section{Materials and Methods}

This descriptive cross-sectional study, conducted in March 2019, utilized a paper-based questionnaire survey to establish the availability of educational resources within anesthesia degree programs in Ethiopia. The students were recruited for anesthesia degree program after they successfully completed high school and they must pass the Ethiopian university entrance exam.

Data was collected via a standardized questionnaire, based on the Ethiopian HERQA recommendations. The questionnaire assessed availability of educational resources for preservice anesthesia training programs in eight areas, categories relating to the broad components of the structure and process; these are classrooms, office space, skills development, clinical practice site, information technology, library, student amenities, and financing. For each area, expected resources or items are specified and defined within the standards. Standards are categorized according to recommendation as "must [have]" and "should [have]" (Supplementary Material 1).

"Must [have]" indicators describe the basic minimum standards that must be met by all institutions delivering anesthesia training programs. "Should [have]" indicators are those standards expected according to international consensus and which anesthesia programs should aim towards for the purposes of quality improvement, though which are not required as a minimum standard for program delivery and may vary according to stage of development of the anesthesia program, In total, 96 indicators were utilized to assess the anesthesia education programs, 71 (74\%) were basic standards and 25 (26\%) were standards for quality improvement.

The questionnaire was distributed to heads of department of anesthesia at five of the six anesthesia training institutions in the Amhara region. A period of three weeks was provided for completion and return of questionnaires.

For each area performance achievement of the recommended standards was rated, according to a three-point scale, as "completely achieved", "partially achieved" or "not achieved". Where the set standard was in accordance with best practice recommendations for anesthesia schools and basic anesthesia education, this would constitute "completely achieved"; where more than half of the requirements were fulfilled, the indicator was rated as "partially achieved"; and where the resource availability fell below half of the requirements, that indicator was rated as "not achieved". Completed questionnaire data was analyzed using SPSS version 20 and is presented descriptively.

In order to keep the ethical soundness of the research, an ethical approval letter (ref. no 867/2011) was obtained from the institutional review board (IRB) of the University of Gondar College of Medicine and Health Sciences after clarifying the purpose of the study. Furthermore, the 
Institutional Review Board of the University of Gondar College of Medicine and Health Sciences approved the verbal informed consent process. The anesthesia training institutions were informed as to the purpose of this study. The participants were also informed about the purpose of the study and verbal consent was obtained.

\section{Results}

Two anesthesia training program sites completed the questionnaire, a $40 \%$ response rate and representing one third of the Amhara region anesthesia training sites. These two sites both provide Bachelor of Anesthesia degree-level non-physician training programs, with one also providing a masters-level program. Between them, these programs admit 70 students per year and current have approximately 180 registered anesthesia students across the two sites.

Evaluation of the 96 standard indicators used to assess attainment of educational resources for anesthesia degree training programs revealed that neither the basic standard indicators, nor quality improvement indicators were met. The standard requirements for classrooms, offices for staff, skills laboratory, clinical practice site, information technology facilities, library, student amenities, and financial resource were not completely achieved in any category. The attainment rate was $50 \%$ or below for all but one area. The area (category) with the highest attainment of the recommended standards was "clinical practice site" with an $81.3 \%$ attainment rate for the 16 recommendations within this area. Financial requirements were the least attained, with the five recommendations for this category $100 \%$ "not achieved". Achievement of the recommended basic standards are further illustrated in Table 1.

Achievement of the secondary quality improvement standards were also poor, as illustrated in Table 2, with attainment below $50 \%$ in all categories. Quality improvement standard indicators related to office space, student amenities and financial resources were 100\% "not achieved". The highest attainment of quality improvement indicators were noted in classrooms, library and clinical practice site indicators.

\section{Discussion}

Ensuring the quality of higher education is a priority agenda in both the Education Sector Development Program IV and the Growth and Transformation Plan of Ethiopia. In Ethiopia, the need to train more health workers, coupled with rapid expansion in medical knowledge, presents a serious challenge to the quality of professional health education across all sectors, including for anesthetists.

Clinical learning environments, including classrooms, quality of teaching, supervision, and facilities, are associated with achievement in medical education. ${ }^{4}$ Student perceptions of their learning environment are associated with both learning outcomes and attitudes towards study. ${ }^{7}$ An effective learning environment requires a sufficient number of teaching and learning tools for the student cohort, including physical space for classrooms. ${ }^{1}$ A qualitative analysis of midwifery and anesthesia training programs in Ethiopia by Kibwana et al reported emerging themes of high student numbers, lack of infrastructure and equipment, and poor clinical case exposure due to insufficient coordination of clinical activities. ${ }^{3}$

Educational resources are a basic component of training programs in higher education. Based on the performance indicators corresponding to each of the eight areas-classrooms, offices for staff, skills laboratory, clinical practice site, information technology facilities, library, student amenities, and financial resource - the target achievement rate was $50 \%$ or below in all but one. Full achievement for

Table I Educational Resources for Preservice Anesthesia Program Training: Basic Standards

\begin{tabular}{|c|c|c|c|c|c|}
\hline \multirow{2}{*}{$\begin{array}{l}\text { Area } \\
\text { No. }\end{array}$} & \multirow[t]{2}{*}{ Area/Category } & \multirow{2}{*}{$\begin{array}{l}\text { No. of Basic Standards Corresponding to } \\
\text { Area }\end{array}$} & \multicolumn{3}{|c|}{ Achievement of Basic Standards (\%) } \\
\hline & & & $\begin{array}{l}\text { Not } \\
\text { Achieved }\end{array}$ & $\begin{array}{l}\text { Partially } \\
\text { Achieved }\end{array}$ & $\begin{array}{l}\text { Completely } \\
\text { Achieved }\end{array}$ \\
\hline 1 & Class rooms & 10 & $30 \%$ & $20 \%$ & $50 \%$ \\
\hline 2 & Office space for staff & 8 & $25 \%$ & 37.5 & $37.5 \%$ \\
\hline 3 & Skills laboratory & 13 & $15.4 \%$ & $76.9 \%$ & $7.7 \%$ \\
\hline 4 & Clinical practices site & 16 & 0 & $18.7 \%$ & $81.3 \%$ \\
\hline 5 & Information technology (IT) facilities & 3 & $75 \%$ & $25 \%$ & 0 \\
\hline 6 & Library facilities & 11 & $9 \%$ & $45.5 \%$ & $45.5 \%$ \\
\hline 7 & Student amenities & 5 & $40 \%$ & $40 \%$ & $20 \%$ \\
\hline 8 & Financial resource & 5 & $100 \%$ & 0 & 0 \\
\hline
\end{tabular}


Table 2 Educational Resources for Preservice Anesthesia Program Training: Quality Improvement Standards

\begin{tabular}{|c|c|c|c|c|c|}
\hline \multirow[t]{2}{*}{$\begin{array}{l}\text { Area } \\
\text { No. }\end{array}$} & \multirow[t]{2}{*}{ Area/Category } & \multirow[t]{2}{*}{$\begin{array}{l}\text { No. of Standards for Quality } \\
\text { Improvement Corresponding to Area }\end{array}$} & \multicolumn{3}{|c|}{$\begin{array}{l}\text { Achievement of Quality } \\
\text { Improvement Standards (\%) }\end{array}$} \\
\hline & & & $\begin{array}{l}\text { Not } \\
\text { Achieved }\end{array}$ & $\begin{array}{l}\text { Partially } \\
\text { Achieved }\end{array}$ & $\begin{array}{l}\text { Completely } \\
\text { Achieved }\end{array}$ \\
\hline I & Classrooms & 2 & 0 & $50 \%$ & $50 \%$ \\
\hline 2 & Office for staff & I & $100 \%$ & 0 & 0 \\
\hline 3 & Skill laboratory & 6 & $50 \%$ & $50 \%$ & 0 \\
\hline 4 & Clinical practices site & 5 & $40 \%$ & $20 \%$ & $40 \%$ \\
\hline 5 & Information technology facility (IT) & 3 & $25 \%$ & $75 \%$ & 0 \\
\hline 6 & Library & 3 & 0 & $75 \%$ & $25 \%$ \\
\hline 7 & Student amenities & 2 & $100 \%$ & 0 & 0 \\
\hline 8 & Financial resource & 3 & $100 \%$ & 0 & 0 \\
\hline
\end{tabular}

standard classroom related indicators was 50\% for both basic and quality improvement standards. Office space for staff and library facility indicator achievement rates were low. Achievement of all standards for financial resource and information technology facilities were nil.

Due to the practical nature of anesthesia training, skills laboratories are an important training resource. ${ }^{5,8}$ In the current study, achievement of all of the basic recommended standards for skills laboratories was 7.7\% and achievement of all quality improvement standards was nil. The basic standard indicators for skills laboratories were usually partially achieved (76.9\%), as laboratories did not incorporate all of the required items. Underequipped skills laboratories pose a problem to development of clinical competencies. ${ }^{3}$ A study by Kibwana et al in 2016 assessing the knowledge and skills of anesthesia graduates in Ethiopia reported only $54.7 \%$ of graduates had achieved the recommended minimum number of endotracheal intubations, and less than $10 \%$ of students believed that skills laboratories had adequate resources and staff. ${ }^{2}$

Targeted efforts to support students during training include safe campus environments, counselling and support units and programs, and support for students with disabilities. Basic standards for student amenities were fully achieved in only $20 \%$, with no quality improvement indicators achieved. This lack of student support, coupled with poorly resourced learning environments, falling below the required minimum standards, could lead to poor performance of learners and ultimately nonattainment of required competencies for progression and graduation, or may impact on quality and safety of anesthesia provision.
With the rapid expansion of training programs to fill the gaps in anesthesia workforce density, the need for educational resources has also grown. Expansion of programs and introduction of new training programs must be accompanied by resources to achieve and maintain the required standards of educational institutions and programs. Furthermore, vacancies within training programs should take into consideration the available educational resource to ensure that quantity does not compromise on quality.

This study is limited by the low response rates from regional facilities. There are currently around 20 institutions offering non-physician anesthesia degree level training programs in Ethiopia, and six in the Amhara region. The results of this study, therefore, represent one third of regional programs, and only around $10 \%$ of national programs. However, the two responding institutions both have well-established programs of more than five years' duration, and this study provides a snapshot into the educational resources available for preservice, non-physician, degree level anesthesia training programs in Ethiopia.

Educational resources for preservice anesthesia training programs at responding institutions in Ethiopia were found to be inadequate and below the required national standards. Regular audit and review of resources within higher education are essential to maintain quality assurance, engage stakeholders and improve learning environments. Expansion of training programs to address the shortfalls in the surgical workforce, particularly within anesthesia, should be accompanied by the necessary resources for high quality program delivery. 


\section{Acknowledgments}

The authors wish to thank the responding Schools of Anesthesia within Ethiopia for provision of valuable information to inform this study.

\section{Funding}

There is no funding to report.

\section{Disclosure}

The authors report no conflicts of interest in this work.

\section{References}

1. Carr C, Johnson P. Eyes on the prize: linking pre-service education to outcomes. Int $J$ Gynaecol Obstet. 2015;130:S2. doi:10.1016/j. ijgo.2015.03.003

2. Kibwana S, Woldemariam D, Misganaw A, et al. Preparing the health workforce in Ethiopia: a cross-sectional study of competence of anesthesia graduating students. Educ Health. 2016;29(1):3. doi:10.4103/1357-6283.178931
3. Kibwana S, Haws R, Kols A, et al. Trainers' perception of the learning environment and student competency: a qualitative investigation of midwifery and anesthesia training programs in Ethiopia. Nurse Educ Today. 2017;55:5-10. doi:10.1016/j.nedt.2017.04.021

4. O'Sullivan PS. What's in a learning environment? Recognizing teachers' roles in shaping a learning environment to support competency. Perspect Med Educ. 2015;4(6):277-279. doi:10.1007/s40037-0150234-4

5. Sullivan KR, Gelb AW. Preface. Challenges in anaesthesia education. Best Pract Res Clin Anaesthesiol. 2012;26(1):1-2. doi:10.1016/j. bpa.2012.03.002

6. Chiu M, Tarshis J, Antoniou A, et al. Simulation-based assessment of anesthesiology residents' competence: development and implementation of the Canadian National Anesthesiology Simulation Curriculum (CanNASC). Survey Anesthesiol. 2017;61(2):32. doi:10.1097/01. sa.0000515830.16043.99

7. Colbert-Getz JM, Kim S, Goode VH, et al. Assessing medical students' and residents' perceptions of the learning environment: exploring validity evidence for the interpretation of scores from existing tools. Acad Med. 2014;89(12):1687-1693. doi:10.1097/ ACM.0000000000000433

8. Walker IA, Bashford T, Fitzgerald J, Wilson IH. Improving anesthesia safety in low-income regions of the world. Curr Anesthesiol Rep. 2014;4(2):90-99. doi:10.1007/s40140-014-0056-7

\section{Publish your work in this journal}

Advances in Medical Education and Practice is an international, peerreviewed, open access journal that aims to present and publish research on Medical Education covering medical, dental, nursing and allied health care professional education. The journal covers undergraduate education, postgraduate training and continuing medical education including emerging trends and innovative models linking education, research, and health care services. The manuscript management system is completely online and includes a very quick and fair peer-review system. Visit http://www.dovepress.com/testimonials.php to read real quotes from published authors. 